\title{
Biomechanical Analysis of Micro-implants Lingual Straight Wire Appliance during Retracting Maxillary Anterior Teeth
}

\author{
Análisis Biomecánico de Microimplantes con Dispositivo de Alambre Recto \\ Lingual Durante la Retracción de Dientes Maxilares Anteriores
}

Hui-Qing Long'; Jing Xuan; Hee-Moon Kyung ${ }^{2}$; Li Bing ${ }^{1} \&$ Xiu-Ping Wu'

LONG, H. Q.; XUAN, J.; KYUNG, H. M.; BING, L. \& WU, X. P. Biomechanical analysis of micro-implants lingual straight wire appliance during retracting maxillary anterior teeth. Int. J. Morphol., 36(4):1386-1393, 2018.

SUMMARY: This study aimed to establish three-dimensional finite element models of micro-implants-lingual straight wire appliance and to investigate the effects of different wire patterns on the initial displacement of the maxillary anterior teeth and the stress of the periodontal ligament and tooth root during retracting maxillary anterior teeth in lingual orthodontics. A three-dimensional geometric models of maxilla with maxillary dentition was established using Cone-beam CT scan . Three types of maxilla models including microimplants and Duet-Slot Lingual Bracket appliance with three different arch wires ( model A: 0.016 inch $\times 0.022$ inch stainless steel square wire; modelB: 0.016 inch stainless steel round wire; model C: double wire of 0.016 inch $\times 0.022$ inch stainless steel square wire + anterior teeth 0.016 inch stainless steel round wire) were assembled by Unigraphics NX 8.5 software. The labial intrusion force and lingual retraction force were simulatively loaded to obtain initial displacement of the anterior teeth and the stresses of each tooth root and periodontal ligament, using three-dimensional finite element calculation software Ansys Workbench 15. The initial displacement of the lateral incisors was close to the bodily movement; and central incisors and lateral incisors slightly extruded. Compared with group A and group C, canine teeth appeared obviously horizontal "arched effect" by crown labial tipping in group B. The stress distribution of the tooth root and periodontal ligament was minimal and uniform in the group $\mathrm{C}$. The $0.016 \times 0.022-$ in stainless steel rectangular wire combined with 0.016- in stainless steel round wire used in the anterior teeth can better control the torque of the maxillary anterior teeth for space close in lingual orthodontics. Moreover, the stress distribution of tooth root and periodontal ligament is even, which is difficult to damage the periodontal ligament or result in external resorption of tooth root.

KEY WORDS: Lingual orthodontics; Morphology; Three-dimensional finite element models; Biomechanics; Archwires.

\section{INTRODUCTION}

Lingual orthodontics is widely recognized and accepted by adult orthodontic patients because of its relatively beautiful features. However, compared with labial orthodontics, excessive lingual inclination of the maxillary anterior teeth and vertical and horizontal "arched effect" of dental arch easily appeared in the space closure stage during lingual orthodontics, because of large variability of anterior tooth lingual surface, small effect of bracket spacing on the rigidity and friction of the arch wire, and small bracket span between the orthodontic force point and the tooth impedance center (Lombardo et al., 2012; Long et al., 2013; Antoszewska-Smith et al., 2017).This has affected the orthodontics effect, and limited the clinical application of lingual orthodontics. In this study we investigated the biomechanics effects of three different wire types applied the retraction force and the labial intrusive force in newly designed Duet-slot lingual bracket featuring with occlusal and lingual slots by using finite element analysis (FEA). We examined the effect of initial tooth movement and stress distribution of periodontal ligament (PDL) and tooth root for providing the lingual technique with valuable information to achieve the best orthodontic result.

\section{MATERIAL AND METHOD}

Establishment of 3D finite element models of microimplants-lingual straight wire appliance during retracting maxillary anterior teeth. One normal cranial bone with normal tooth, complete dentition and symmetrical arch were

\footnotetext{
${ }^{1}$ Department of Orthodontics, School of Dentistry, Shanxi Medical University, Taiyuan, China.

${ }^{2}$ Department of Orthodontics, School of Dentistry, Kyungpook National University, Daegu, Korea.

Funding: The National Natural Science Fund of China, No.81400553?The International Cooperation Project of Science and Technology Department of Shanxi Province(China - Korea), No. 2015081030.
} 
selected and scanned with cone-beam CT (KAVO, German). Data with DICOM file were output. Two-dimensional CT scan results were introduced into Mimics 17.0 software. 3D information of maxilla and dentition was extracted by adjusting threshold so that the images of the maxilla and dentition were clearly visible. The maxillary models containing the entire dentition were obtained by the Boolean operation to simulate the perfectly aligned teeth after orthodontic treatment. Above 3D models were modified with software Unigraphics NX ( version 8.5, Siemens Inc, Germany) to establish models of lingual brackets and arch wires. The geometric models of the Duet-slot lingual Bracket were based on standard sample of DLB from the School of Stomatology, Kyungpook National University, Daugu, South Korea (Fig. 1). In accordance with clinical conditions and properties of biomaterials, the above mentioned models were classified into cortical bone, cancellous bone, tooth, periodontal ligament, arch wire, traction hook, coil spring, micro-implant and bracket. The periodontal ligament (PDL) was simulated as a $0.2 \mathrm{~mm}$ thick layer around the roots, and the cortical bone was $0.5 \mathrm{~mm}$ thick (Kojima \& Fukui, 2006; Kojima et al., 2007, 2012). Isotropic and linearly elastic behavior was assumed for all materials, and the mechanical properties were taken from previous studies (Pelsue et al., 2009; Kojima \& Fukui, 2012; Xia et al., 2013; Facchini et al., 2017) (Table I).

Finite element analysis software ANSYSnsys Workbench 15 (ANSYS, USA) was used to generate tetrahedral 10-node element. It is assumed that the maxillary surface is a fixed end. The teeth-brackets, periodontal ligament-teeth, alveolar bone-periodontal ligament, and cortical bone-cancellous bone were connected with bonded; bracket-archwire was connected with No separation. Therefore, free axial rotation movement of the arch-wire in the brackets was allowed, while friction between the archwire and brackets along the axial direction was ignored. The established 3D finite element models of micro-implantslingual straight wire appliance are exhibited in Figure 2.

In the system studied, the $\mathrm{x}$-axis was the midsagittal line of the dental arch on the occlusal view, The direction from right to the left of arch was defined as $+X$. The direction of $Y$ was perpendicular to the $X$ on the plane, and the direction from Labial surface to the lingual surface of the central incisors was defined as $+Y$. The direction of $Z$ was perpendicular to the $X Y$ plane. The occlusal direction towards gingival direction referred to $+Z$ (Fig. 2).

Loading conditions. The position of the microimplants(MIA) located the apical areas of the first and second molars for retraction the anterior teeth was assumed to be 8 $\mathrm{mm}$ from the alveolar crest (Fig. 3). The micro-implants situated the labial region between the two central incisors were assumed to apply vertical traction for clinic simulation the intrusion anterior from the threads fixed in the labial crown using light-cured resins (Fig. 4). The retraction hook $(\mathrm{RH})$ was placed bilaterally between the lateral incisor and the canine at a height of $6 \mathrm{~mm}$. Retraction force of $1.5 \mathrm{~N}$ from the RH to MIA traction was applied, and the additional intrusion force $(50 \mathrm{~g})$ from the two incisors was combined to simulate the effect on labial crown torque.

The working wires for en-masse anterior retraction with MIA by sliding mechanics were divided into three groups: 0.016 X 0.022- in stainless steel(SS) rectangular wire (group A); 0.016 -in SS round wire (group B); 0.016 X 0.022in SS + 0.016-in SS (group C) . the initial displacement of the anterior dentition and the stress of each their root and periodontal ligament were analyzed.
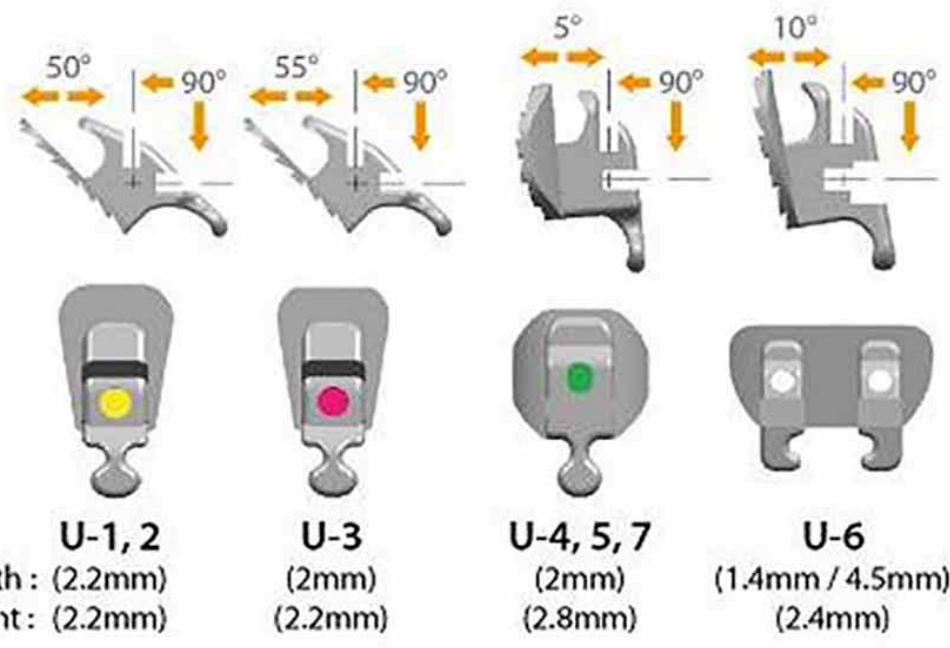

Fig. 1. Dimensions of Duet-slot lingual Bracket (DLB). 
Table I. Material properties required in the three-dimensional finite element models.

\begin{tabular}{lcc}
\hline Mechnical parameters & Elastic modulus (MPa) & Poisson's ratio \\
\hline Dentin & 20300 & 0.30 \\
Periodontal ligament & 50 & 0.45 \\
Cortical bone & 13700 & 0.30 \\
Cancellous bone & 1370 & 0.30 \\
Traction hook/bracket/archwire & 206000 & 0.30 \\
Micro-implant & 103400 & 0.35 \\
\hline
\end{tabular}
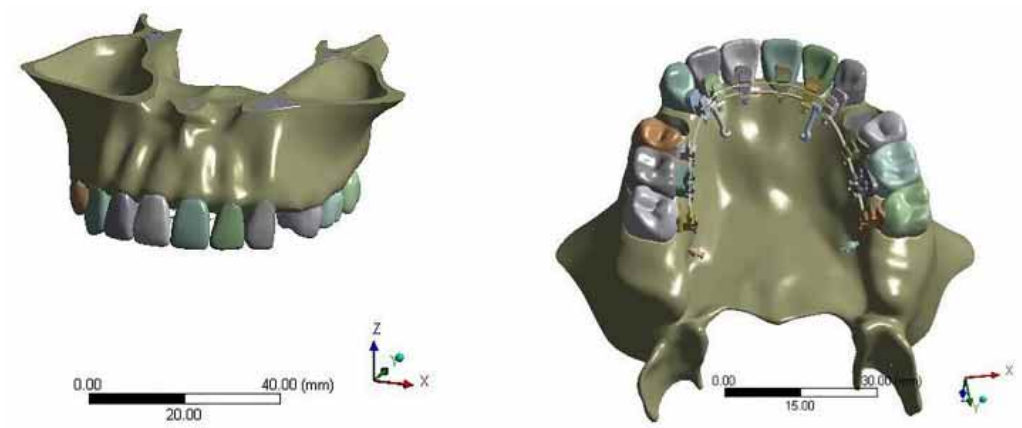

Fig.2. FEM of MIA-LSW orthodontic treatment.
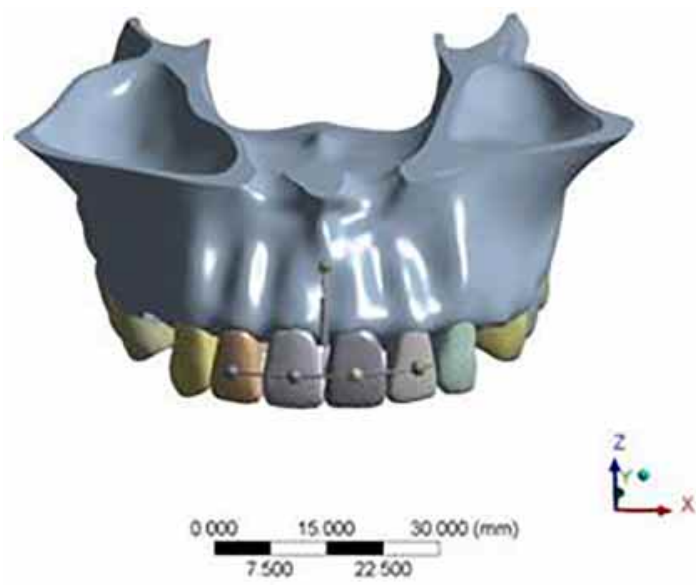

Fig. 3. Retraction force from MIA located between 1st molar and 2nd molar to hook.
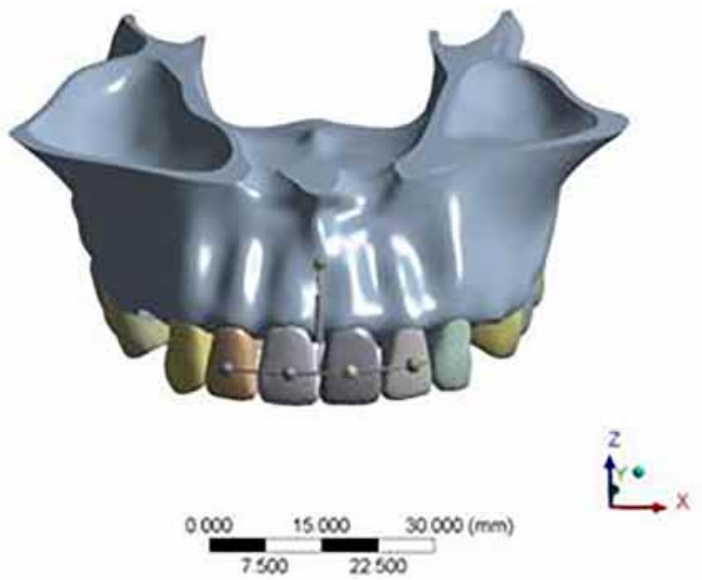

Fig. 4. Labial vertical intrusion force from MIA to hook situated between the two incisors.

\section{RESULTADOS}

Displacement of anterior dentition. In accordance with 3D finite element analysis models and three groups of loading conditions, initial displacement of anterior dentition was calculated and results were displayed in Figure 5. The initial displacement was the largest in the incisal edge of lateral incisors compared with the canine central incisors. The displacement gradually decreased from the incisal edge to the root apex. The displacement of anterior teeth of group $\mathrm{C}$ was more uniform than that of groups A and B (Table II).

Horizontal displacement of anterior dentition. As shown in Figure, anterior dentition of the three groups presented obvious expansion of dental arch in canine area because the crown and root of canine were both moved labially. Moreover, the amount of displacement on the cuspid of canine in the group B was approximately twice than that in the groups A and C. As shown in Table II, central incisors presented the tipping movement with crown moved medially and apex moved distally in the horizontal direction. The horizontal displacement of the lateral incisors was similar to that of the central incisors with more pronounced mesial tipping.

Sagittal displacement of anterior dentition. The maximum of the sagittal displacement was at the incisal edge of the lateral incisors in all experimental groups. In particular, the lateral incisors in the group B presented obvious tipping movement with crown towards lingual direction. In the groups $\mathrm{A}$ and $\mathrm{C}$, the central incisors moved close to the lingual bodily movement (Fig. 7). Moreover, the difference of crown and root displacement was smaller in the group C than in the group A. The canine teeth presented tipping movement of crown to distal direction and apex to mesial direction in the groups $\mathrm{A}$ and $\mathrm{C}$, however, in group $\mathrm{B}$ the canine moved mesially both crown and root (Table III). These results indicate that canines have the tendency of mesial eversion. A pronounced horizontal "arched effect" was seen in the group B.

Vertical displacement of anterior dentition. The dental cervix and root apex of the lateral incisors demonstrated remarkable intrusion in all groups A, B and C. The incisal edge of lateral incisor was elongated. The maximum vertical displacement was much smaller in the groups $\mathrm{A}$ and $\mathrm{C}$ than that in the group B (Figs. 8 and 9). The central incisors 
Table II. Initial displacement of crown and root on X,Y,Z axis of the anterior teeth in three groups (mm).

\begin{tabular}{|c|c|c|c|c|c|c|c|c|c|}
\hline & \multicolumn{2}{|c|}{ A group } & \multicolumn{3}{|c|}{ B group } & \multicolumn{3}{|c|}{ C group } & \multirow[b]{2}{*}{$\mathrm{Z}$ axis } \\
\hline & $\mathrm{X}$ axis & Yaxis & $\mathrm{Z}$ axis & $\mathrm{X}$ axis & Yaxis & $\mathrm{Z}$ axis & $\mathrm{X}$ axis & Yaxis & \\
\hline U1crown & $7.96 \mathrm{e}-05$ & $1.77 \mathrm{e}-04$ & $-9.91 e-05$ & $3.88 \mathrm{e}-06$ & $3.66 \mathrm{e}-04$ & $-2.61 \mathrm{e}-04$ & $7.70 \mathrm{e}-05$ & $1.82 \mathrm{e}-04$ & $-1.01 \mathrm{e}-04$ \\
\hline U1root & $-4.00 \mathrm{e}-06$ & $3.95 \mathrm{e}-05$ & $-2.15 e-05$ & $-5.44 \mathrm{e}-06$ & $2.69 \mathrm{e}-05$ & $-1.35 e-05$ & $-3.87 e-06$ & $4.01 \mathrm{e}-05$ & $-2.05 e-05$ \\
\hline U2root & $-9.01 \mathrm{e}-06$ & $2.68 \mathrm{e}-05$ & $4.80 \mathrm{e}-05$ & $-1.93 e-06$ & $7.46 \mathrm{e}-05$ & $1.01 \mathrm{e}-04$ & $-8.79 e-06$ & $2.62 \mathrm{e}-05$ & $4.65 \mathrm{e}-05$ \\
\hline U3crown & $-5.00 \mathrm{e}-05$ & $3.10 \mathrm{e}-04$ & $-1.88 \mathrm{e}-04$ & $-1.08 \mathrm{e}-03$ & $-2.16 \mathrm{e}-04$ & $7.11 \mathrm{e}-05$ & $-3.69 e-05$ & $3.14 \mathrm{e}-04$ & $-1.90 \mathrm{e}-04$ \\
\hline U3root & $-8.59 \mathrm{e}-06$ & $-1.58 \mathrm{e}-05$ & $-3.41 \mathrm{e}-06$ & $1.06 \mathrm{e}-05$ & $-1 . .59 \mathrm{e}-05$ & $-7.67 e-05$ & $-8.78 \mathrm{e}-06$ & $-1.57 \mathrm{e}-05$ & $-2.51 \mathrm{e}-06$ \\
\hline
\end{tabular}
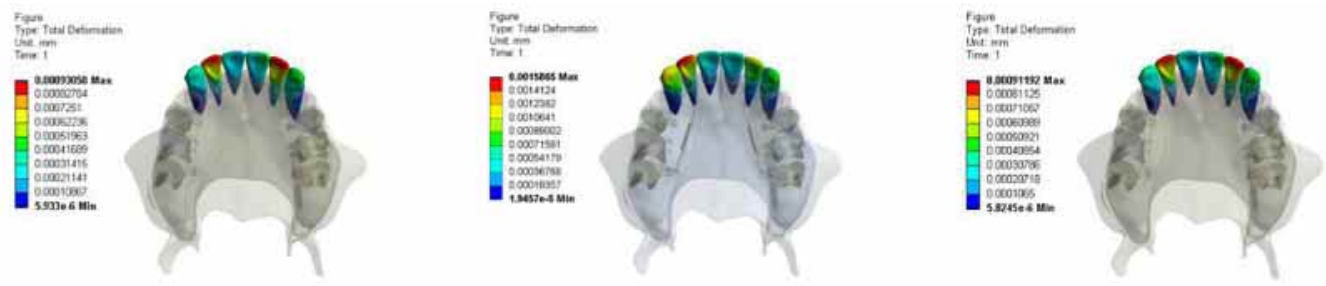

A
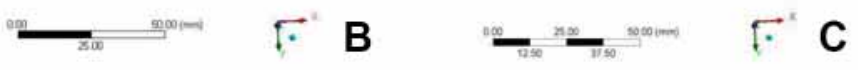

F.

Fig. 5. Displacement of anterior teeth.
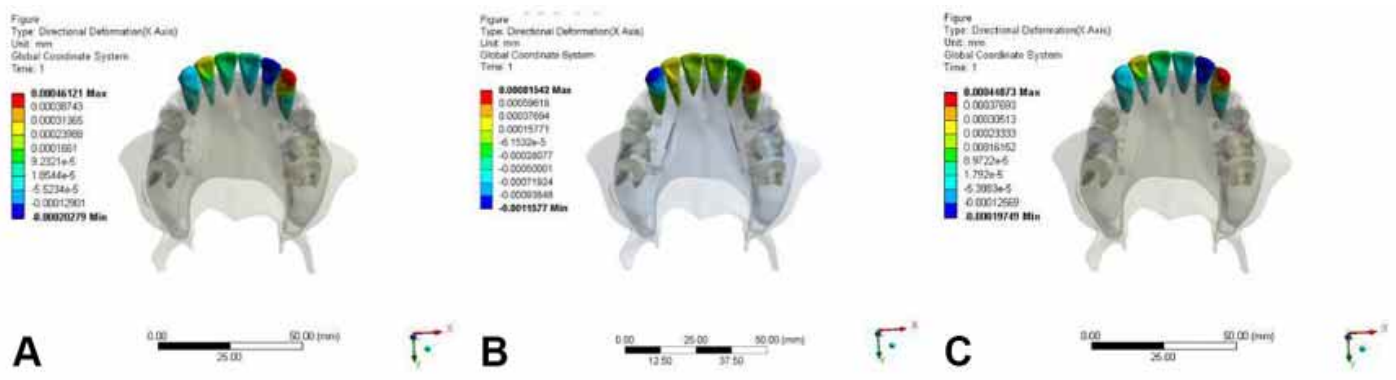

Fig. 6. Horizontal displacement of anterior teeth. U1 Right center incisor U2 Right lateral incisor U3 Right canine).
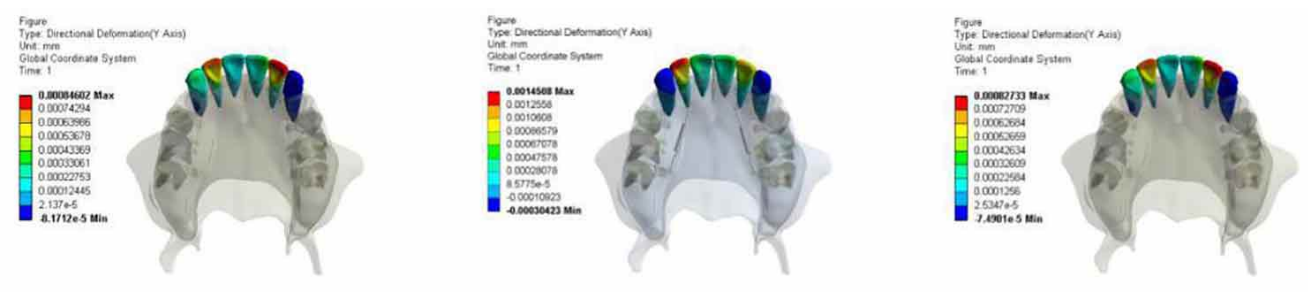

\section{A}
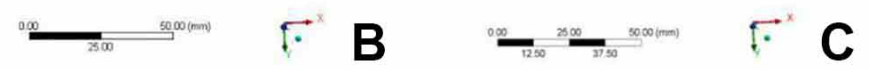

F.

Fig. 7. Sagittal displacement of anterior teeth.

Table III. Initial displacement of crown and root on Y axis of the anterior teeth in three groups (mm).

\begin{tabular}{|c|c|c|c|c|c|}
\hline Group & & Crown & Root & Difference & Absolute \\
\hline \multirow{3}{*}{ A } & U1 & $1.77 \mathrm{e}-04$ & $3.95 \mathrm{e}-05$ & $1.38 \mathrm{E}-04$ & $1.38 \mathrm{E}-04$ \\
\hline & U2 & $7.26 \mathrm{e}-04$ & $2.68 \mathrm{e}-05$ & $6.99 \mathrm{E}-04$ & $6.99 \mathrm{E}-04$ \\
\hline & U3 & $3.10 \mathrm{e}-04$ & $-1.58 \mathrm{e}-05$ & $3.26 \mathrm{E}-04$ & $3.26 \mathrm{E}-04$ \\
\hline \multirow{3}{*}{ B } & U1 & $3.66 \mathrm{e}-04$ & $2.69 \mathrm{e}-05$ & 3.39E-04 & $3.39 \mathrm{E}-04$ \\
\hline & U2 & $1.17 \mathrm{e}-03$ & $7.46 \mathrm{e}-05$ & $1.10 \mathrm{E}-03$ & $1.10 \mathrm{E}-03$ \\
\hline & U3 & $-2.16 \mathrm{e}-04$ & $-1.59 \mathrm{e}-05$ & $-2.00 \mathrm{E}-04$ & $2.00 \mathrm{E}-04$ \\
\hline \multirow{3}{*}{$\mathrm{C}$} & U1 & $1.82 \mathrm{e}-04$ & $4.01 \mathrm{e}-05$ & $1.42 \mathrm{E}-04$ & $1.42 \mathrm{E}-04$ \\
\hline & U2 & $7.04 \mathrm{e}-04$ & $2.62 \mathrm{e}-05$ & $6.78 \mathrm{E}-04$ & $6.78 \mathrm{E}-04$ \\
\hline & U3 & $3.14 \mathrm{e}-04$ & $-1.57 \mathrm{e}-05$ & $3.30 \mathrm{E}-04$ & $3.30 \mathrm{E}-04$ \\
\hline
\end{tabular}



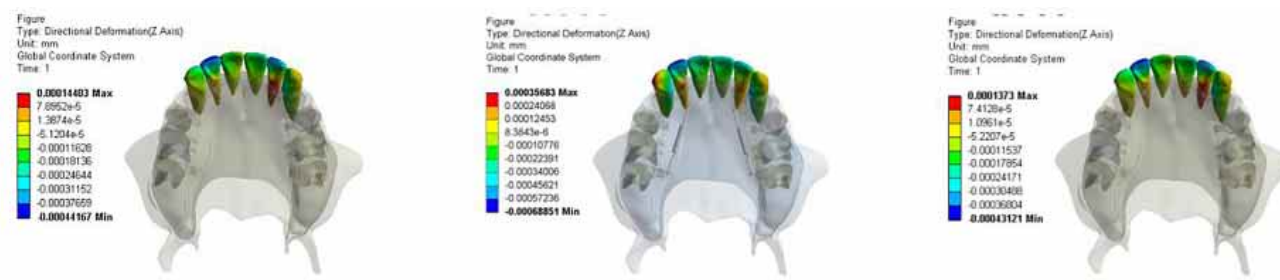

A

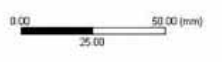

$F^{x} B$

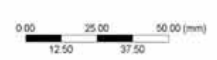

$\Gamma^{x} \mathrm{C}$
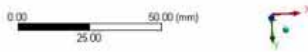

Fig. 8. Vertical displacement of anterior teeth.

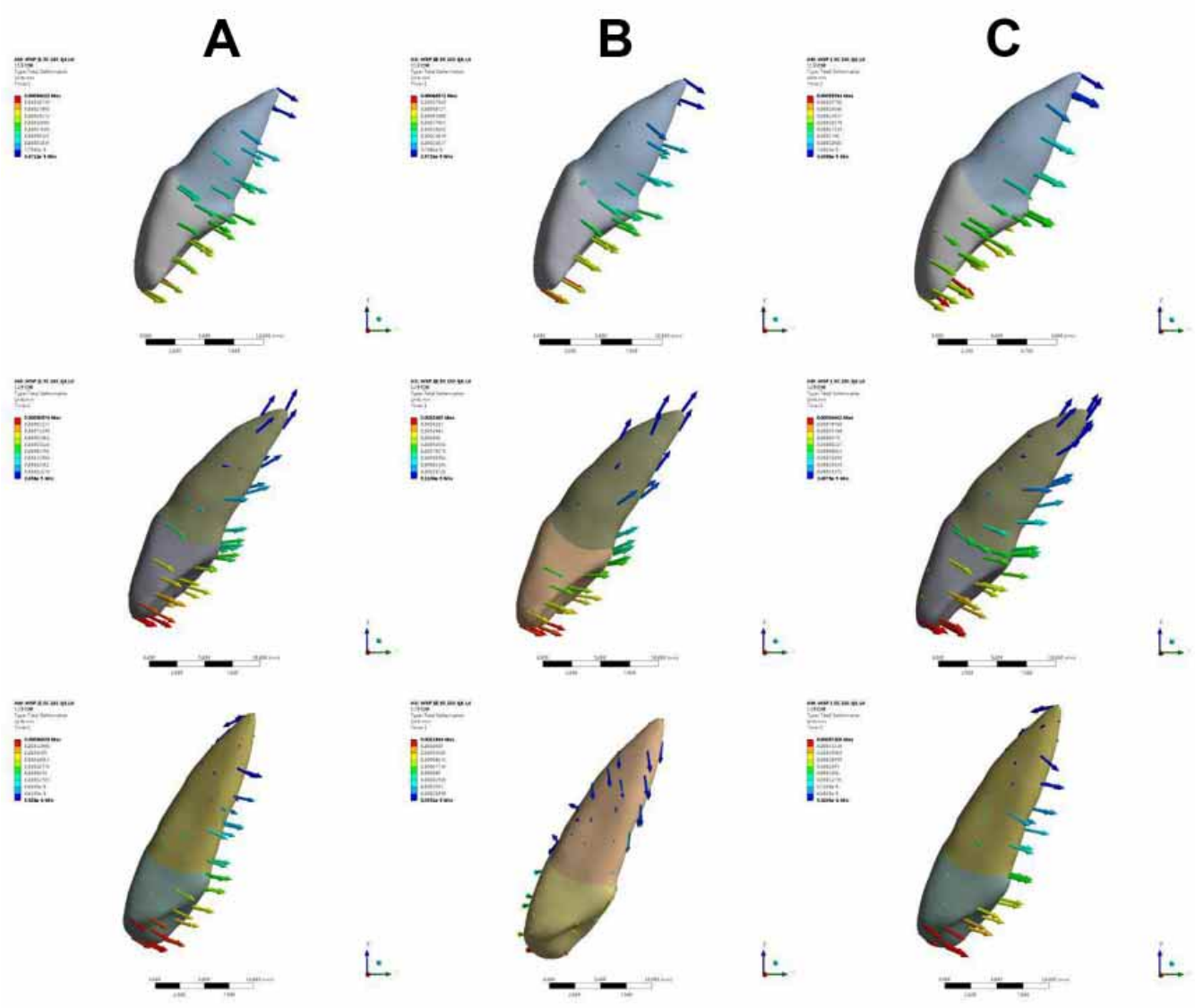

Fig. 9. Initia displacement on $\mathrm{X}, \mathrm{Y}, \mathrm{Z}$ axis of the anterior teeth in three groups (mm).
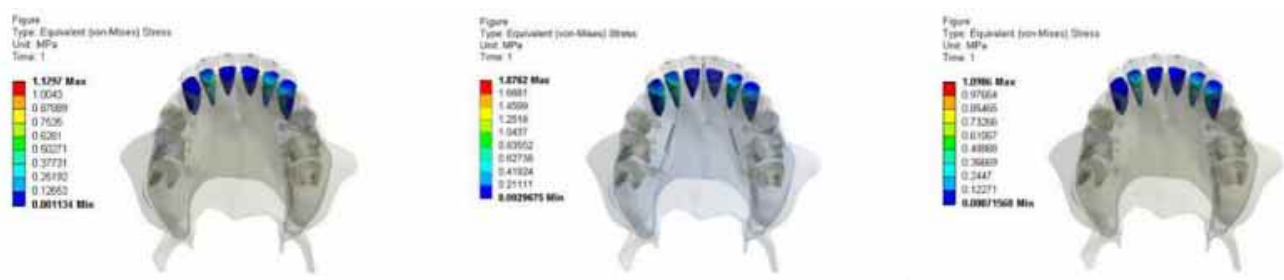
A
F $B$
$-\ldots$
F $\mathbf{C}$
$F$

Fig. 10. Equivalent stress of anterior root. 
in the three groups were extruded. Also, the canines in the groups $\mathrm{A}$ and $\mathrm{C}$ were extruded. However, the canine presented crown intrusion, and apex extrusion in the group $\mathrm{B}$, Which indicated the canine obviously tent to crown lingual tipping movement.

Anterior tooth root stress. Figure 10 showed the distribution of S1 and S3 from the cervical margin to the apex of the maxillary anterior tooth root, The maximum (S1) stress was produced and mostly concentrated near the cervix on the lateral incisors and the canine. This suggested that dental cervix of maxillary anterior teeth on lingual side was a critical stress-strain region, which was consistent with the tendency of secondary tooth movement after bone reconstruction. In the group A, the stress of $1.1297 \mathrm{MPa}$ was produced in the cervix of lateral incisors. In the group $\mathrm{B}$, the maximum stress of $1.8762 \mathrm{MPa}$ was produced in the lingual cervix of lateral incisors and canine teeth. In the group $\mathrm{C}$, the stress of $1.0986 \mathrm{MPa}$ was produced in the cervix of lateral incisors. It is thus evident that the root stress of anterior teeth was smallest in models in the group $\mathrm{C}$; moreover, the stress distribution was uniform and reasonable, and the external root resorption was difficult to occur.

Stress distribution in the periodontal ligament of anterior teeth.Stress distribution of periodontal ligament was similar to the stress of tooth root in the three groups, and was significantly concentrated at cervix of lateral incisors and canines . Maximum stress of periodontal ligament was distributed at the cervix of lateral incisors on the lingual side in the group A (0.14059 MPa), in the group B which located the mesial cervix of lateral incisors (S1 0.25341 $\mathrm{MPa}$ ), however, the cervix of lateral incisors was concentrated on the lingual side in the group C $(0.13733$ $\mathrm{MPa}$ ). The stress of periodontal ligament was larger in the group B than in the groups A and C. The stress of periodontal ligament in the group $\mathrm{C}$ was smallest compared with the groups A and B (Fig. 11).
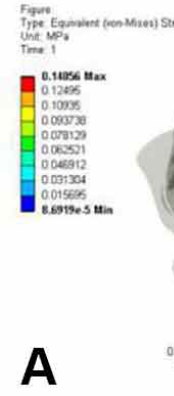
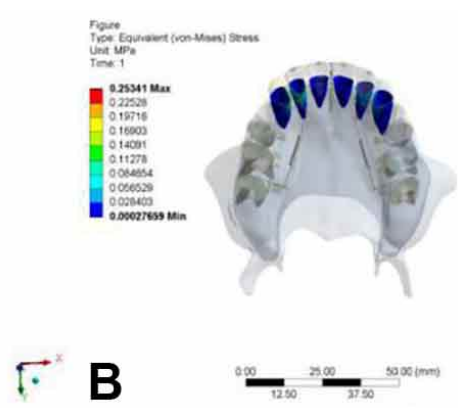
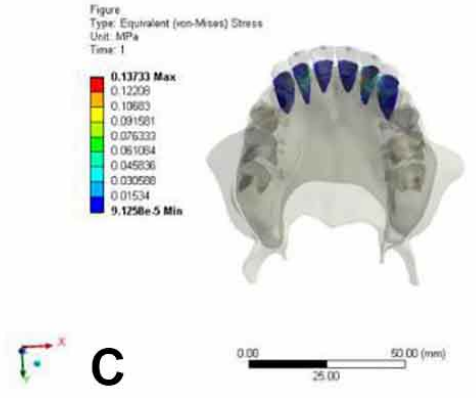

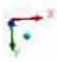

Fig. 11. Equivalent stress of anterior PDL.

\section{DISCUSSION}

Lingual orthodontic system invented by Dr. Kurz and Dr. Fujita in 1970s, because of its highest esthetics, has developed rapidly in recent years.Compared with the labial orthodontocs, lingual orthodontics is difficult to control the maxillary incisors torque during the movement of retraction. The expression of the torque of the lingual brackets is usually achieved by the use of a personalized lingual resin base.However, full-size archwire can cause discomfort and difficulty in arch wire insertion. Therefore, after the dental arch is completely aligned and leveled, the 0.016 inch $\times 0.022$ inch SS is commonly used to close the space. But, the torque provided by the bracket itself is not sufficient to provide the required torque in some clinical applications. In the case of tooth extraction, the "arched effect" easily appears in lingual orthodontics, Thus the micro-implant anchorage is inserted in palatal alveolar bone between the first molar and the second molar for en-masse space closure in lingual orthodontics. In some patients, however, retroclined anterior teeth with only retraction force can cause a torque lost of anterior teeth. Dr Liang analyzed initial displacement of the tooth and the stress and strain distribution of the periodontal ligament in 3D finite element models, and found that the lingual retraction force was more likely to cause anterior teeth crown lingual tipping movement (Liang et al., 2009). It is essential to achieve the better torque control towards root lingual movement. Thus, in this study we designed a labial vertical intrusive force in addition to the horizontal retraction force for space closure by palatal microimplant.

Duet Lingual Orthodontic Bracket (DLB) featuring two slots used in this study has been more applied in and 
outside China.The occlusal slot with veitical direction is convenient for insertion and removal of archwire, The lingual slot with horizontal insertion direction is closer to the CR compared to the occlusal slot, and facilitates the control of the torque and the mesiodistal tipping.So, two types arch wires can be simultaneously inserted in the two slot.This study focused on analysis of the biomechanical characteristics about the stress and movement of anterior teeth in 3D finite element models after inserting 0.016 inch $\times 0.022$ inch stainless steel square wire (lingual slot), 0.016 inch stainless steel round wire (lingual slot), 0.016 inch $\times$ 0.022 inch stainless steel square wire (lingual slot) + anterior teeth 0.016 inch stainless steel round wire (occlusal slot).

With the rapid development of digital technology, the finite element analysis has become an effective research method of oral biomechanics (Geron et al., 2004; Cattaneo et al., 2015; Wang et al., 2017). 3D finite element method is an important method for studying the movement of orthodontic teeth (Murakami \& Wakabayashi, 2014).The reaction of teeth to sliding mechanics can be analyzed by using finite element analysis (FEA) (Namburi et al., 2017). With 3-dimensional (3D) computer models, various conditions can be simulated by varying the simulation parameters. The initial reactions of the teeth, periodontal ligament (PDL), and alveolar bone can be evaluated qualitatively and quantitatively.

The torque control of the anterior teeth has always been the focus of lingual orthodontic design using microimplants during retracting maxillary anterior teeth. In this study, the results showed that it presented noticeable horizontal "arched effect", and the initial displacement of anterior teeth was tipping movement (with lingual crown and labial apex movement) in group B with only 0.016 -in round wire, whereas the initial displacement of lateral incisors was almost translationin the groups $\mathrm{A}$ and $\mathrm{C}$, also in the group $\mathrm{C}$ the anterior teeth appeared better bodily movement than in group A. The possible reasons for the biomechanical difference was the 0.016 inch $\times 0.022$ inch $S W$ can provide the better torque control of the anterior teeth than 0.016 inch RW. In addition, when inserting two wire in the occlusal and lingual slot, round wires in the occlusal slot can maintain the arch form and control the rotation of anterior teeth.

Although we designed the intrusion force vector during retraction, the central incisors still showed light extrusion in all groups. From mechanics, the intrusive force generates two orthodontic effects: intrusion of the maxillary incisor and an effect equal to lingual root torque. But ,in orthodontic practice, a heavy intrusive force could cause root absorption more easily. Therefore, in Lingual orthodontic treatment, , it is more important to control torque with light lingual retraction force and appropriately intrusive force to counteract the tendency of lingual crown tipping (Melsen, 2001). In the horizontal direction, initial displacement of mesioclination could be seen in the central incisors and lateral incisors in the three groups. However, Maximum initial displacement in the group B was twice as much as that in thegroups $\mathrm{A}$ and $\mathrm{C}$. The stress was uneven in the group B. Canine teeth presented labial displacement and widened dental arch in the three groups, but tipping displacement was not obvious in the group $\mathrm{C}$ than in the group $\mathrm{A}$.

Lee reported that the maximum stress that the periodontal ligament can sustain is $0.026 \mathrm{Mpa}$; if the strength exceeds the limit, the periodontal ligament will suffer permanent damage (Lee, 1965). In this study, the maximum stress of the periodontal ligament was $0.14059 \mathrm{MPa}$ and $0.13733 \mathrm{MPa}$ in the groups A and C, respectively, which was far less than $0.026 \mathrm{Mpa}$, and could not cause permanent damage to the periodontal ligament. Nevertheless, the maximum stress of the periodontal ligament was 0.25341 $\mathrm{MPa}$ in the group $\mathrm{B}$, which was close to the critical value and had a risk of injury to the periodontal ligament. Moreover, the stress of tooth root was relatively large in the group B, suggesting the possibility of external resorption of tooth root. So, the group $\mathrm{C}$ with DW can better control the movement of anterior teeth in the space closure stage during lingual orthodontics.

The 3D-FEA analysis reveal that the group C namely double wire is highly efficient in torque control compared with the conventional single round wire or rectangular wire in lingual orthodontics. These results suggest that en-masse bodily movement of anterior teeth seems to be difficult though increase the vertical intrusion force by using MIA. However, these results are right only for the initial movement, which is produced by elastic deformation of the PDL. This is a limitation of this study. Long-term orthodontic movement might not be the same as the initial movement.

LONG, H. Q.; XUAN, J.; KYUNG, H. M.; BING, L. \& WU, X.P. Análisis biomecánico de microimplantes con dispositivo de alambre recto lingual durante la retracción de dientes maxilares anteriores. Int. J. Morphol., 36(4):1386-1393, 2018.

RESUMEN: Este estudio tuvo como objetivo establecer modelos tridimensionales de elementos finitos de microimplantes linguales de alambre recto e investigar los efectos de diferentes patrones de alambre en el desplazamiento inicial de los dientes maxilares anteriores y el estrés del ligamento periodontal y la raíz del diente durante la retracción lingual sobre los dientes anteriores del hueso maxilar en ortodoncia. Se establecieron modelos geométricos tridimensionales del hueso maxilar con dentición utilizando una exploración por tomografía computarizada de haz cónico. Tres tipos de modelos maxilares, incluidos los microimplantes 
y el dispositivo Duet-Slot Lingual Bracket con tres arcos diferentes (modelo A: 0.016 pulgada $\times 0.022$ pulgada alambre cuadrado de acero inoxidable; modelo B: alambre redondo de acero inoxidable de 0.016 pulgadas; alambre cuadrado de acero inoxidable de 0.016 pulgada $\times 0.022$ pulgada y alambre redondo de acero inoxidable de 0.016 pulgada) ensamblados por el software Unigraphics NX 8.5. La fuerza de intrusión labial y la fuerza de retracción lingual se cargó simultáneamente, para obtener el desplazamiento inicial de los dientes anteriores y las tensiones de cada raíz dental y ligamento periodontal, usando el software tridimensional de cálculo de elementos finitos Ansys Workbench 15. El desplazamiento inicial de los incisivos laterales se relacionaba al movimiento corporal; mientra que los incisivos centrales e incisivos laterales se mostraron ligeramente extruidos. Comparado con el grupo A y el grupo $\mathrm{C}$, los dientes caninos presentaron un "efecto arqueado" horizontal por la inclinación labial de la corona en el grupo B. La distribución del estrés de la raíz del diente y el ligamento periodontal fue mínima y uniforme en el grupo C. El alambre rectangular de acero inoxidable combinado con el alambre redondo de acero inoxidable de 0.016 usado en los dientes anteriores puede controlar mejor el torque de los dientes maxilares anteriores para cerrar el espacio en ortodoncia lingual. Además, la distribución del estrés de la raíz del diente y del ligamento periodontal es pareja, lo que dificulta dañar el ligamento periodontal o provocar una resorción externa de la raíz del diente.

PALABRAS CLAVE: Ortodoncia lingual; Morfología; Modelos tridimensionales de elementos finitos; Biomecánica; Arcos

\section{REFERENCES}

Antoszewska-Smith, J.; Sarul, M.; yczek, J.; Konopka, T. \& Kawala, B. Effectiveness of orthodontic miniscrew implants in anchorage reinforcement during en-masse retraction: A systematic review and meta-analysis. Am. J. Orthod. Dentofacial Orthop., 151(3):440-55, 2017.

Cattaneo, P. M.; Dalstra, M. \& Melsen, B. The finite element method: a tool to study orthodontic tooth movement. J. Dent. Res., 84(5):428-33, 2015.

Facchini, F. M.; Filho, M. V.; Vedovello, S. A.; Cotrim, F. A.; CotrimFerreira, A. \& Tubel, C. A. Wire Roughness Assessment of 0.016" × $0.022 "$ the Technique Lingual Orthodontics. J. Contemp. Dent. Pract., 18(4):295-9, 2017.

Geron, S.; Romano, R. \& Brosh, T. Vertical forces in labial and lingual orthodontics applied on maxillary incisors--a theoretical approach. Angle Orthod., 74(2):195-201, 2004.

Kojima, Y. \& Fukui, H. A numerical simulation of tooth movement by wire bending. Am. J. Orthod. Dentofacial Orthop., 130(4):452-9, 2006.

Kojima, Y. \& Fukui, H. Numerical simulations of canine retraction with Tloop springs based on the updated moment-to-force ratio. Eur. J. Orthod., 34(1):10-8, 2012.

Kojima, Y.; Kawamura, J. \& Fukui, H. Finite element analysis of the effect of force directions on tooth movement in extraction space closure with miniscrew sliding mechanics. Am. J. Orthod. Dentofacial Orthop., 142(4):501-8, 2012.

Kojima, Y.; Mizuno, T. \& Fukui, H. A numerical simulation of tooth movement produced by molar uprighting spring. Am. J. Orthod. Dentofacial Orthop., 132(5):630-8, 2007.
Lee, B. W. Relationship between tooth-movement rate and estimated pressure applied. J. Dent. Res., 44(5):1053, 1965.

Liang, W.; Rong, Q.; Lin, J. \& Xu, B. Torque control of the maxillary incisors in lingual and labial orthodontics: a 3-dimensional finite element analysis. Am. J. Orthod. Dentofacial Orthop., 135(3):316-22, 2009.

Lombardo, L.; Stefanoni, F.; Mollica, F.; Laura, A.; Scuzzo, G. \& Siciliani, G. Three-dimensional finite-element analysis of a central lower incisor under labial and lingual loads. Prog. Orthod., 13(2):154-63, 2012.

Long, H.; Zhou, Y.; Pyakurel, U.; Liao, L.; Jian, F.; Xue, J.; Ye, N.; Yang, X.; Wang, Y. \& Lai, W. Comparison of adverse effects between lingual and labial orthodontic treatment. Angle Orthod., 83(6):1066-73, 2013.

Melsen, B. Tissue reaction to orthodontic tooth movement--a new paradigm. Eur. J. Orthod., 23(6):671-81, 2001.

Murakami, N. \& Wakabayashi, N. Finite element contact analysis as a critical technique in dental biomechanics: a review. J. Prosthodont. Res., 58(2):92-101, 2014.

Namburi, M.; Nagothu, S.; Kumar, C. S.; Chakrapani, N.; Hanumantharao, C. H. \& Kumar, S. K. Evaluating the effects of consolidation on intrusion and retraction using temporary anchorage devices-a FEM study. Prog. Orthod., 18(1):2, 2017.

Pelsue, B. M.; Zinelis, S.; Bradley, T. G.; Berzins, D. W.; Eliades, T. \& Eliades, G. Structure, composition, and mechanical properties of Australian orthodontic wires. Angle Orthod., 79(1):97-101, 2009.

Wang, X. D.; Lei, F. F.; Liu, D. W.; Zhang, J. N.; Liu, W. T.; Song, Y. \& Zhou, Y. H. Miniscrew-assisted customized lingual appliances for predictable treatment of skeletal Class II malocclusion with severe deep overbite and overjet. Am. J. Orthod. Dentofacial Orthop., 152(1):104$15,2017$.

Xia, Z.; Jiang, F. \& Chen, J. Estimation of periodontal ligament's equivalent mechanical parameters for finite element modeling. Am. J. Orthod. Dentofacial Orthop., 143(4):486-91, 2013.

Corresponding author:

Li Bing \& Xiu-Ping Wu

Stomatology Hospital

Shanxi Medical University

63 Xinjian Road,Taiyuan 030001

CHINA

Email: libing-1975@163.com

Received: 26-06-2018

Accepted: 07-08-2018 